\title{
Article \\ Fracture Toughness Analysis of Aluminum (Al) Foil and Its Adhesion with Low-Density Polyethylene (LPDE) in the Packing Industry
}

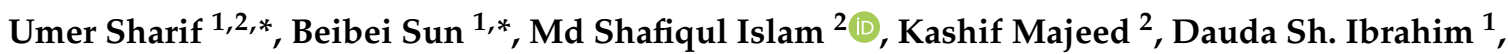 \\ Orelaja Oluseyi Adewale ${ }^{1}$, Naseem Akhtar ${ }^{3}$, Zaki Ismail Zaki ${ }^{4}$ and Zeinhom M. El-Bahy ${ }^{5}$ \\ 1 School of Mechanical Engineering, Southeast University, Nanjing 211189, China; \\ sidauda.mct@buk.edu.ng (D.S.I.); 233179946@seu.edu.cn (O.O.A.) \\ 2 Department of Mechanical Engineering, Blekinge Institute of Technology, 37179 Karlskrona, Sweden; \\ shafiqul.islam@bth.se (M.S.I.); kama10@bth.se (K.M.) \\ 3 Department of Chemistry, The Government Sadiq College Women University, Bahawalpur 63100, Pakistan; \\ drnaseem@gscwu.edu.pk \\ 4 Department of Chemistry, College of Science, Taif University, P.O. Box 11099, Taif 21944, Saudi Arabia; \\ zakimohamed@tu.edu.sa \\ 5 Department of Chemistry, Faculty of Science, Al-Azhar University, Nasr City, Cairo 11884, Egypt; \\ zeinelbahy@azhar.edu.eg \\ * Correspondence: 233179945@seu.edu.cn (U.S.); bbsun@seu.edu.cn (B.S.)
}

\section{check for}

updates

Citation: Sharif, U.; Sun, B.; Islam, M.S.; Majeed, K.; Ibrahim, D.S.; Adewale, O.O.; Akhtar, N.; Zaki, Z.I.; El-Bahy, Z.M. Fracture Toughness Analysis of Aluminum (Al) Foil and Its Adhesion with Low-Density Polyethylene (LPDE) in the Packing Industry. Coatings 2021, 11, 1079. https://doi.org/10.3390/ coatings11091079

Academic Editor: Yingyi Zhang

Received: 31 July 2021

Accepted: 2 September 2021

Published: 6 September 2021

Publisher's Note: MDPI stays neutral with regard to jurisdictional claims in published maps and institutional affiliations.

Copyright: (c) 2021 by the authors. Licensee MDPI, Basel, Switzerland. This article is an open access article distributed under the terms and conditions of the Creative Commons Attribution (CC BY) license (https:// creativecommons.org/licenses/by/ $4.0 /)$.

\begin{abstract}
Liquid food packages consist of various polymers films, which are bonded together with Aluminum foil (Al-foil) using adhesion or by direct heat. The main aim of this research was to define important material properties such as fracture toughness and some FE-simulation material model parameters such as damage initiation, damage evolution, and the adhesion between Al-foil and low-density polyethylene (LDPE) film. This investigation is based on both physical experiments and FE simulations in ABAQUS with and without initial cracks of different lengths for comparison purposes. The final FE model in ABAQUS was used to compare the numerical input parameters in an extensive study with the ambition to investigate the materials' parameters in cases with or without adhesion between laminates. Finally, the relation between the theoretical and experimental results for Al-foil using linear elastic fracture mechanics and modified strip yield model were shown, and the fracture toughness was calculated for two different thicknesses of Al-foil.
\end{abstract}

Keywords: fracture toughness; aluminum foil; LDPE film; laminate; FE model

\section{Introduction}

Due to the continuous development of packaging industries, it has become possible to buy well-stored food distributed from far away locations [1]. An important step is to understand the mechanical and fracture properties of the packaging material. Packaging materials generally comprise various layers of paperboard, polymers and aluminum foil (Al-foil) [2]. Al-foil and the low-density polyethylene (LDPE) film are studied in this paper. Paperboard together with these materials is broadly utilized as a material structure in aseptic food packages. The Al-foil is utilized as a proficient barrier against oxygen and light in food packages $[3,4]$.

The final packaging material is exposed to diverse loading conditions during its lifetime: forming, folding, filling, distribution, storage, handling, and eventually opening, wasting and recycling by the consumer [5]. Al-foil is incapable of withstanding high local strains like polymer film and the paper layers. Pre-cracks in the Al-foil can subsequently spread into the polymer and the paper layers. Therefore, it is important to recognize the individual and combined fracture behaviors of the Al-foil as well as its adhesion with LDPE layers and their roles as contributors towards the laminated structure when creating an 
opening device mechanism [6,7]. In order to predict the impairment evolution within the laminate, the fracture performance of the Al-foil and the LDPE are first studied distinctly. Numerous studies of the fracture performance of specific packaging material layers, for example, paperboard, are presented in [8-10]. To present the foundation for the study of Alfoil and LDPE, pre-center cracked panels were exposed to in-plane tensile mode I loading for further examination in this study. The bonds amongst the distinctive layers are allocated similar strengths as the induced traction forces generated when the distinctive material layers contract due to stress localization in the tensile tests, therefore leading to separation of the two material layers locally. De-lamination and the level of adhesion are interesting topics [11-16], which must be reviewed in the future. As pointed out in [17], mechanical modeling of polymer materials is still in a relatively premature phase when compared with the advances in metallic materials. A cell model has been developed and applied to study the effect of voids on matrix yielding and localized plastic deformation $[18,19]$. The modified Dugdale model approach was developed to investigate the localized plastic deformation of the single layer in addition to the laminate. The fracture behavior of the Al-foil and LDPE laminate has also been reviewed in previous work in [11,12,20-22]. A common opinion is the huge diversity of failure mechanisms in laminates of distinctive structures. Diverse loading happens at the time during transportation that triggers the opening phenomena of food packages [23]. Linear elastic fracture mechanics (LEFM), Elastic Plastic Fracture mechanics (EPFM) and modified strip yield model theories were used in the investigation of outcomes whilst loading components, response and fracture of material [24].

The purpose of this work was to present the results of the mechanical and fracture behaviors of the Al-foil and its adhesion with LDPE. These results will be used as input to virtual material modeling for calculation of the different package properties. The aim of the discussed approaches should be utilized to create a capable and potential tool for decision making and package improvement with practical and analytical simulation models. This article has three parts: a theoretical part, description of the fracture toughness methods and established practices. It explains important fracture mechanics parameters such as stress intensity factor $\mathrm{K}$, J-integral, from the essential conception and meaning to experimental assessment and test approaches. In Section 3, the material properties are discussed. Experimental setup and experimental results are also presented in this section. Section 4 describes the mechanical behavior of the pre-cracked material and laminates. Analytical models were used to examine the experimental data in this section. The study will hopefully lead to further understanding of each of the laminate parts and how they contribute to crack development in the laminate. The differences in material behavior between adhesion and cohesion will also be investigated to gain further understanding.

\section{Theoretical Model}

\subsection{Fracture Mechanics}

Some theoretical models of fracture mechanics from the literature were used to study the breakage behavior of different materials. There are three different basic modes of loading on a crack tip $[25,26]$. All the three modes have different stress intensity factors at the crack, which is required to propagate the crack $[27,28]$. The stress intensity factors describing different modes of fracture, $K_{I}, K_{I I}$ and $K_{I I I}$, are given by Equations (1)-(3), respectively, while $\sigma_{y}$ is the stress caused by normal force, $\tau_{x y}$ and $\tau_{y z}$ are the shear forces along xy and yz planes, respectively.

$$
\begin{aligned}
k_{I} & =\lim _{x \rightarrow 0} \sigma_{y}(x, 0) \sqrt{2 \pi x} \\
k_{I I} & =\lim _{x \rightarrow 0} \tau_{x y}(x, 0) \sqrt{2 \pi x} \\
k_{I I I} & =\lim _{x \rightarrow 0} \tau_{y z}(x, 0) \sqrt{2 \pi x}
\end{aligned}
$$


The materials' physical properties often depend on their direction or plane. In the case of $\mathrm{Al}$ and LDPE, both materials are assumed to be isotropic because their properties remain the same in all directions. The laminate in this work consists of Al-foil/Adhesive/LDPE. LDPE is, in reality, not linear, but under small strains it can be approximated by a linear elastic material. It can also be considered to be isotropic. The adhesive layer is assumed to have the same mechanical properties as LDPE [29].

By the theory of elasticity, the stress field near the crack tip is a function of the geometry of the specimen location and loading. LEFM explains the stresses surrounding a crack tip, which are given as follows [30]:

$$
\sigma_{i j}=\frac{K}{\sqrt{2 \pi r}} f_{i j}(\theta) a s r \rightarrow 0
$$

Here, " $r$ " is the distance from the crack tip, " $\theta$ " is the angle of the crack plane and " $K$ " is the stress intensity factor, where " $i$ " and " $j$ " are indices values 1 and 2 referring to the Cartesian axes $X_{1}$ and $X_{2}$, and are known as angular functions [30]. The stress intensity factor " $K$ " becomes equal to the fracture toughness at the start of crack growth. The LEFM limiting stress can be mathematically expressed as:

$$
\sigma_{c}=\frac{K_{c}}{\sqrt{\pi a \times \varnothing}}
$$

Here, the above notation is described as: $a=$ half of crack length, $\sigma=$ stress at crack growth (obtained from experiments), and $K_{c}=$ fracture toughness. When inelastic deformation $\mathrm{n}$ is small compared to the crack size, the LEFM theory is valid, which is called small scale yielding (SSY) [31].

\subsection{Model of Modified Strip Yield}

The model of strip yield for a crack, using two elastic solutions given below, defines the elastic plastic behavior, crack under remote tension and crack with closure stress at the tip.

The discontinuous displacement segment was assumed to model the strip yield plastic zone. The initial crack length including the discontinuous displacement segment length is $2(a+1)$, where " 1 " is the length at each end of the discontinuity, which are under equal stress $\sigma_{b}$, and $2 \mathrm{a}$ is the crack length and length " 1 " is the plastic zone represented by nonlinear behavior of materials shown in Figure $1[32,33]$. For calculating the yielding, in thin steel sheets, Dugdale suggested the strip yield model, and later this model was used for a variety of materials. The strip yield model is applicable to polymer materials.

\section{$\sigma_{b}$}

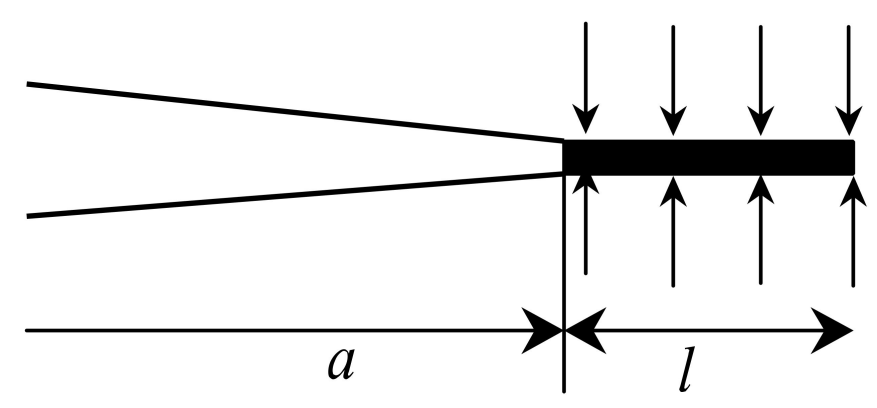

Figure 1. The strip yield model.

The relation between applied stress and crack length can be derived, as written below

$$
\frac{\sigma_{c}}{\sigma_{b}}=\frac{2}{\pi} \arccos \left[\exp \left(-\frac{\pi K_{c}^{2}}{8 a \sigma_{b}^{2}}\right)\right]
$$


Equation (6) is derived for infinite plates. To obtain reasonable results for the finite plate, the correction factor $\varnothing$ from (9) is used to redefine (6), when $a \rightarrow W$, is given by

$$
\frac{\sigma_{c}}{\sigma_{b}}=\frac{2}{\pi} \arccos \left[\exp \left(-\frac{\pi K_{c}^{2}}{8 a \varnothing^{2} \sigma_{b}^{2}}\right)\right]
$$

\subsection{Fracture Toughness}

Fracture toughness and the behavior of crack propagation mainly depend on the material's thickness $[30,31]$. The different values of $K_{I}$ will be produced for specimens with different absolute sizes and standard proportions. This happens because the stress on specimen thickness varies and it continues until the thickness exceeds some critical dimension. After this, $K_{I}$ becomes relatively constant and this material property is known as the plane-strain fracture toughness " $K_{I C}$ " [34]. The load corresponding to defined unstable crack propagation helps to compute fracture toughness. The stress intensity factor, $K$, equals the fracture toughness during crack propagation. The stress for LEFM is given by [30].

$$
k_{c}=\sigma_{0} \sqrt{\pi a} \times \varnothing\left(\frac{a}{w}\right)
$$

In the above expression, " $\sigma_{0}$ " represents remote applied stress, " $\varnothing$ " represents correction factor for center cracked specimen, " $a$ " represents half the crack length, and " $w$ " represents half width of specimen. The geometric correction factor $\varnothing$ for the center crack specimen is

$$
\varnothing\left(\frac{a}{w}\right)=\frac{1-0.0025 \frac{a^{2}}{w}+0.006\left(\frac{a}{w}\right)^{4}}{\cos ^{\frac{1}{2}}\left(\frac{\pi\left(\frac{a}{a}\right)}{2}\right)}
$$

Analytical relations for experimental stress vs. crack length are given by Equation below.

$$
\sigma_{\text {exp }}=\frac{P(a)}{2 B w}
$$

In Equation (10), " $P$ " represents the applied force and " $a$ " represents half of the crack length. The specimen configuration used in Equation (10) are presented in Figure 2.

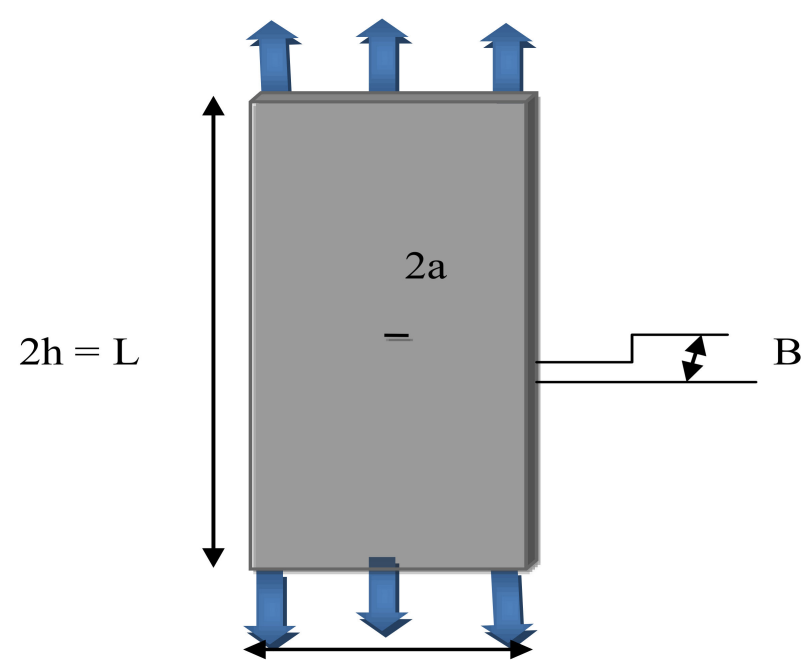

$2 \mathrm{~W}$

Figure 2. Specimen configuration with a centered crack of length 2a [35].

\subsection{Adhesion Behavior}

The maximum force required to break the bond is defined as a measure of adhesion. The measure of the strength of an adhesive bond across an interface is the amount of 
energy needed to break it, i.e., to separate two surfaces. Such a separation may involve the breakage of chemical or van der Waals bonds, and the plastic deformation of one or both of the materials on either side of the interface. The fraction of energy required to break the bonds at the interface is a very small fraction of the total energy necessary for the separation of the two surfaces in all cases where good adhesion is present [36,37]. Most of the mechanical work is used to deform, under stress, the material adjacent to the interface. Therefore, the measured energy of adhesion will be dependent on the ability of the interfacial bonds to sustain stress, as well as on the amount of plastic deformation caused by the above-mentioned stress [38]. In many structures, the use of adhesives is common. To explain the adhesive behavior, separation law can be used. $\tau_{\max }$ is the maximum stress (damage Initiation in ABAQUS) that the adhesive can take and $\delta_{\text {max }}$ (damage Evolution in ABAQUS) is the maximum separation of the bulk material before the adhesive breaks and the bulk material is fully separated [27].

\section{Experimental Study}

The tensile tests were performed using an MTS Qtest100 machine with appropriate clamps manufactured by MTS system corporation, Minneapolis, MN, USA presented in Figure 3. The lower clamp is stationary and the upper one moves up to load the specimen by prescribed displacement. A $2.5 \mathrm{KN}$ load cell was used due to the weight of the clamper. The specimen was placed between the grips and secured properly. The clamped specimen was loaded and extended until it broke or reached a desired displacement. The test speed was adjusted to $10 \mathrm{~mm} / \mathrm{min}$. The initial distance between grips was $230 \mathrm{~mm}$.

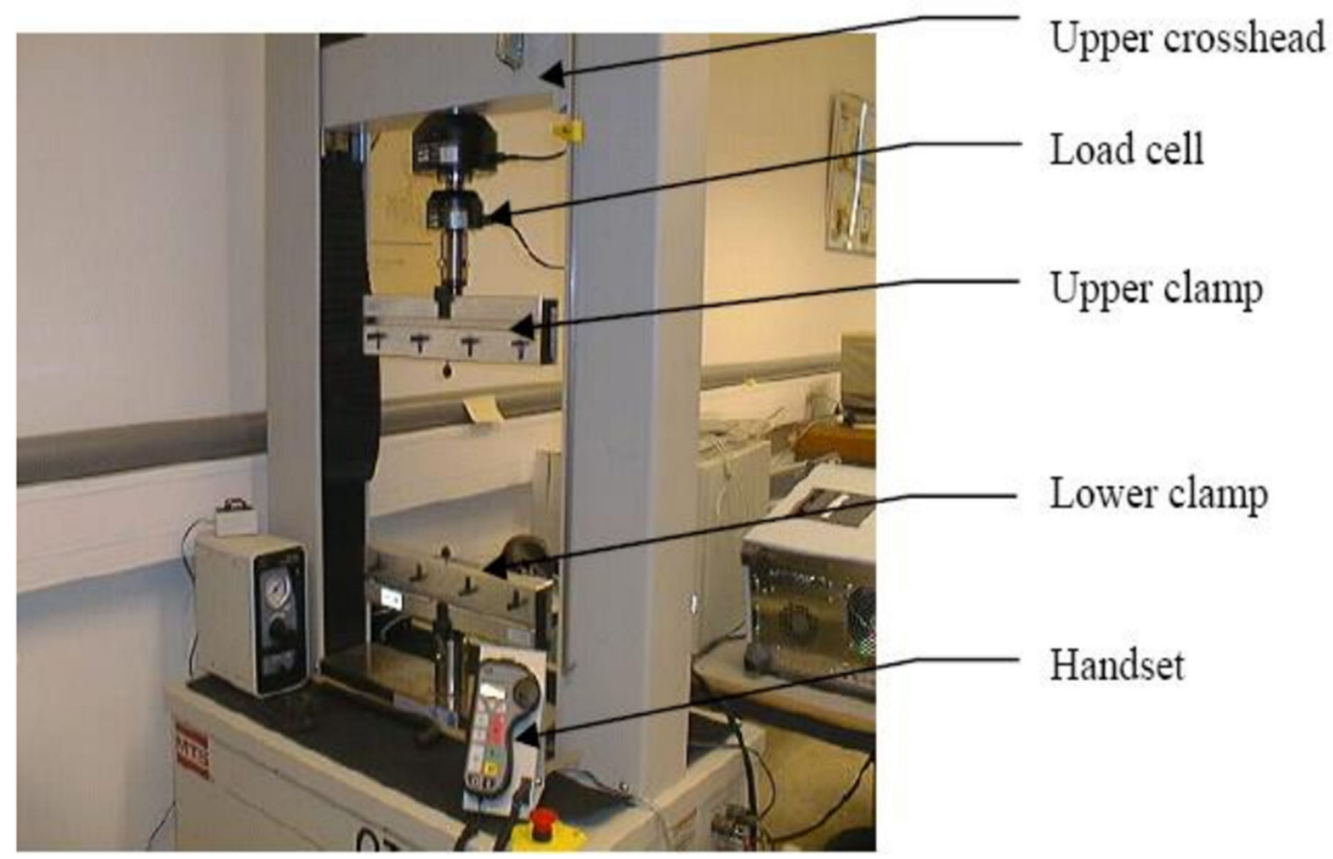

Figure 3. MTS machine at BTH lab.

\subsection{Material Preparation}

The LET/LDPE laminate was manufactured by spraying melted LDPE onto a PET layer. The LDPE layer was extracted from PET with the help of an extruder, as shown in Figure 4. Al foil, Al/LDPE (without adhesion) and Al/Adh/LDPE (with adhesion) were prepared. A simple paper laminating machine was used to make Al bonded with LDPE. The manual was studied, and it was observed that the machine operated at 120 centigrade. Paper was placed on both sides of the lamina to protect the lamina from having direct contact with the heated roller while laminating. A pre-center crack was introduced after the layers had been laminated. The same procedure was followed for the preparation of $\mathrm{Al}$ foil/Adh/LDPE, except that paper gum was used as an adhesive between the layers 
and then a pre-center crack was introduced after laminating the layers. In all cases for Al and LDPE, Al served as the master layer and LDPE as the slave layer. Both LDPE and Al were assumed to have isotropic behavior in this work, although in practice the materials are anisotropic.

\section{LDPE}

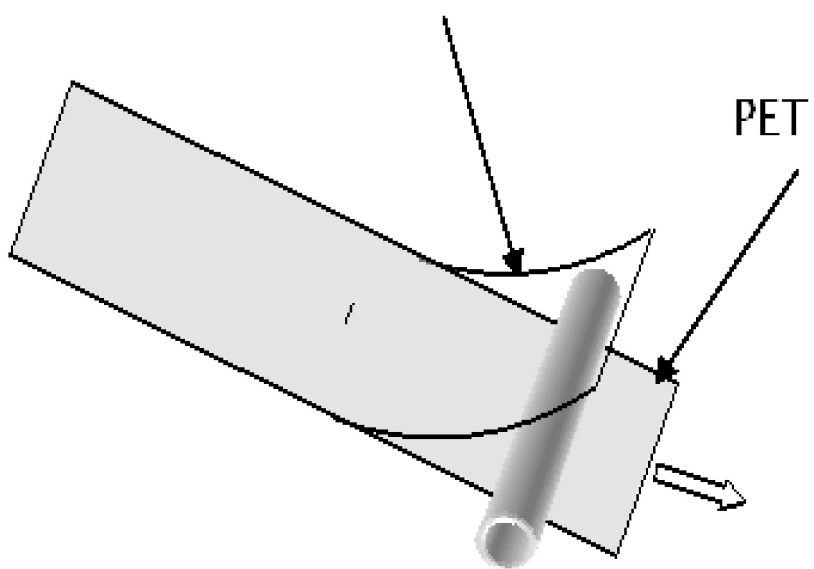

Figure 4. Extrusion of test size LDPE layer from PET laminated with LDPE layers [35].

\subsection{Design of Experiment}

Sample Preparation: Half width $\mathrm{W}$ and height $\mathrm{h}$ from the center were measured with the help of a scale. For each material, Al foil and laminated Al foil, at least five test specimens of $95 \mathrm{~mm} \times 230 \mathrm{~mm}$ size were prepared, as shown in Figure 5. The width of the specimen ( $2 \mathrm{~W}$ equals $95 \mathrm{~mm}$ ) was assumed to be infinite in comparison with the crack length in order to remove the effect of finite size. A steel ruler and knife were utilized to make the specimens and cracks. Taking the gripper of the MTS machine into consideration, a height size greater than $230 \mathrm{~mm}$ specimen was used. Half crack length was made from the center to both directions in order to ensure similar pre-crack tip shapes. While making the specimen of $\mathrm{Al}$ foil, it should be taken into account that no pre-crack was introduced, as $\mathrm{Al}$ foil is very sensitive to handle.
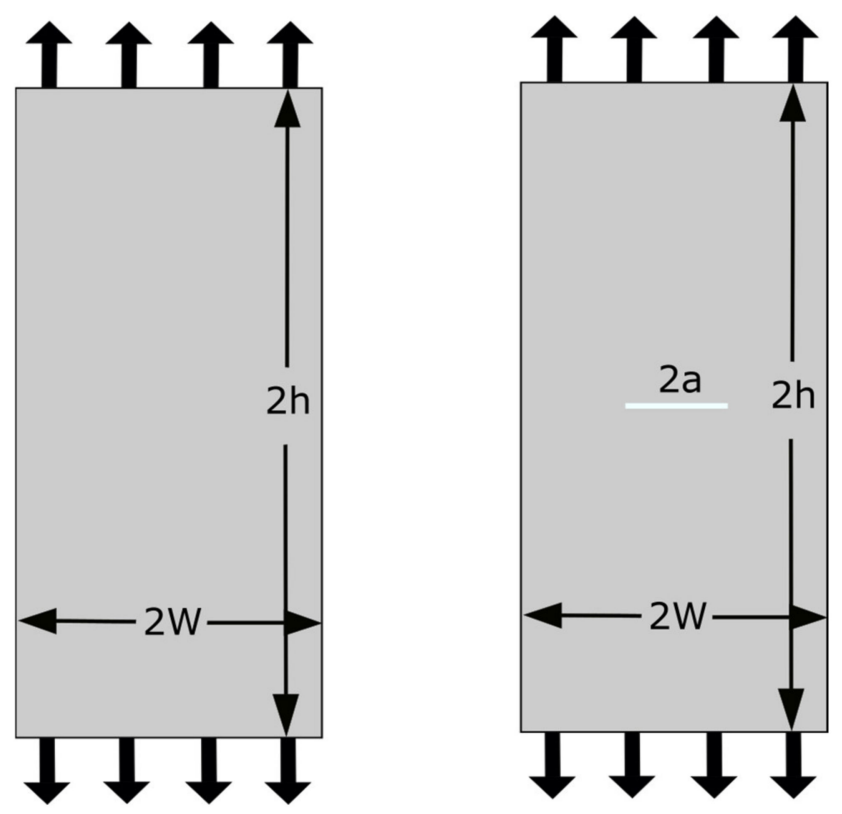

Figure 5. Specimen with center crack and without center crack. 


\subsection{Experimental Testing for Data Collection}

As the test began, the force vs. displacement graph was displayed continually. When there was no pre-crack, the $\mathrm{Al}$ foil, $\mathrm{Al} / \mathrm{LDPE}$, and $\mathrm{Al} / \mathrm{Adh} / \mathrm{LDPE}$ tear around the lower gripper or fail abruptly from the center; however, when there was a pre-crack, the crack advanced down the width in all circumstances, following the centerline. To investigate the influence of adhesion and crack propagation behavior through the lamina, Al/LDPE and $\mathrm{Al} / \mathrm{Adh} / \mathrm{LDPE}$ specimens with initial cracks of various lengths were manually halted at various displacements. The Al-foil utilized had a thickness of 9 microns, while the test specimens were made of a 27-micron thick LDPE. The test cases are presented in Table 1.

Table 1. Test cases.

\begin{tabular}{ccccc}
\hline Sr. No & Test Cases & Crack & Thickness $(\boldsymbol{\mu m})$ & $\begin{array}{c}\text { Dimensions } \\
(\mathbf{m m} \times \mathbf{m m})\end{array}$ \\
\hline 1 & Al Foil & $\begin{array}{c}\text { With and } \\
\text { without crack }\end{array}$ & 9 & $230 \times 95$ \\
\hline 2 & Al Foil/LDPE $/(w / o)$ & $\begin{array}{c}\text { With and } \\
\text { Adh }\end{array}$ & 36 & $230 \times 95$ \\
\hline 3 & Al Foil / Adh $/$ LDPE & $\begin{array}{c}\text { With and } \\
\text { without crack }\end{array}$ & 36 & $230 \times 95$ \\
\hline
\end{tabular}

\subsection{Experimental Results and Discussion}

\subsubsection{Case 1: Aluminum Foil}

Both materials responded similarly in MD and CD because they are both isotropic. If there was no crack in the aluminum foil, it suddenly failed or tore away from the bottom clamp. As a result, LDPE behaved similarly. When both had pre-cracks, the crack spread along the width of the crack, following the centerline. In the case of no crack, more force was required to induce the fracture. As the length of the initial fracture grew longer, the force required to propagate the crack decreased. At least five test samples of each case were generated and tested, as discussed in Section 3.2. Only the greater displacement and force findings are shown in the main text; the remaining results are presented in Appendix A. The cumulative results of all specimens for $\mathrm{Al}$ foil with a crack length of 0 to $45 \mathrm{~mm}$ are shown in Figure 6.

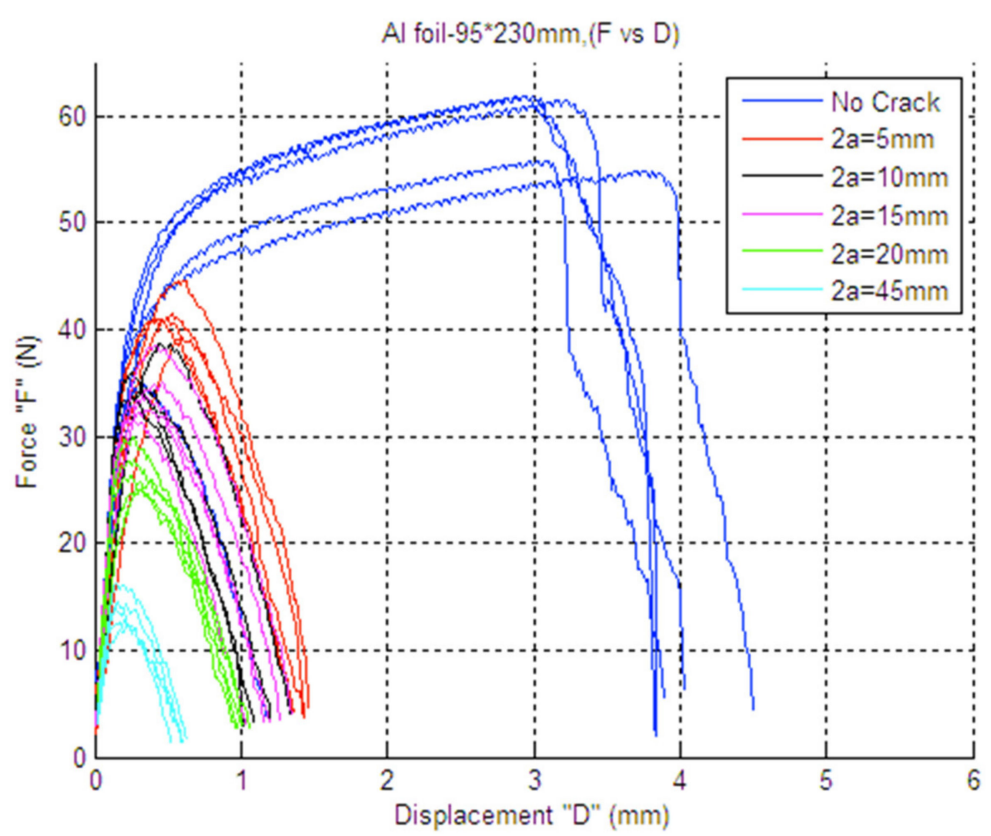

Figure 6. Load vs. displacement of Al-foil (center cracked) of 0-45 mm for all specimens. 
As previously stated, for the calculation of mechanical characteristics and numerical analysis of materials, only higher force and displacement values were taken into account in all circumstances. With no crack, the highest displacement measured in Al-foil was $3.218 \mathrm{~mm}$ when the applied load reached $61.45 \mathrm{~N}$. In the case of a $45 \mathrm{~mm}$ fracture length case with a load of $14.47 \mathrm{~N}$, the minimum extension was $0.16 \mathrm{~mm}$. The findings reveal that a greater force is required to propagate the crack when the crack length is shorter, and that this force reduces as the crack length increases. For fracture lengths ranging from 0 to $45 \mathrm{~mm}$, the results are reported in Figure 7 and Table 2. Experimental results for all the specimens are presented in Appendix A, Figure A1.

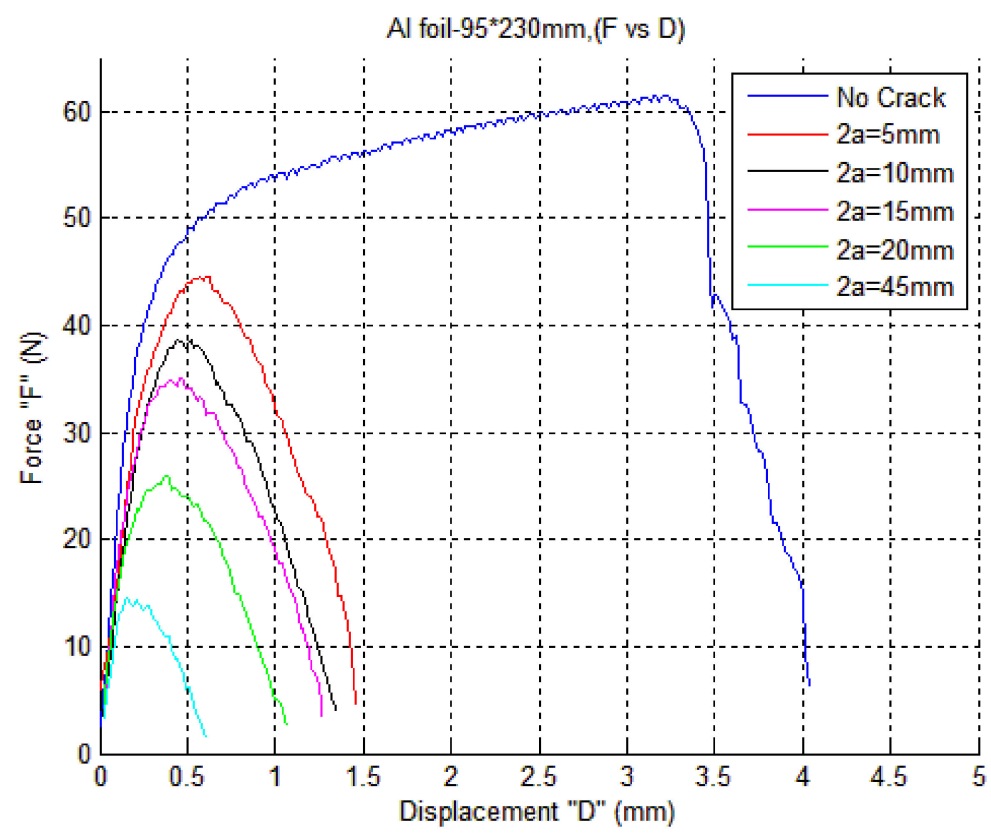

Figure 7. Load vs. displacement of $\mathrm{Al}$ foil (center cracked) of $0-45 \mathrm{~mm}$.

Table 2. Load and displacement of fractured Al foil, thickness B of $9 \mu \mathrm{m}$ and dimensions of $230 \mathrm{~mm} \times 95 \mathrm{~mm}$.

\begin{tabular}{ccc}
\hline $\begin{array}{c}\text { Crack Length (2a) } \\
(\mathbf{m m})\end{array}$ & $\begin{array}{c}\text { Maximum Load (F) } \\
\mathbf{( N )}\end{array}$ & $\begin{array}{c}\text { Extension (D) } \\
(\mathbf{m m})\end{array}$ \\
\hline No Crack & 61.45 & 3.218 \\
\hline 5 & 44.64 & 0.606 \\
\hline 10 & 38.62 & 0.523 \\
\hline 15 & 34.99 & 0.458 \\
\hline 20 & 25.88 & 0.38 \\
\hline 45 & 14.47 & 0.16 \\
\hline
\end{tabular}

\subsubsection{Case 2: Aluminum Foil/LDPE (without Adhesion)}

In the absence of adhesion, the Al-foil broke faster than the LDPE. As a result, LDPE took longer to fail than Al-foil. This is due to the ductility of LDPE. In the presence of a pre-crack, aluminum had a much lower maximum extension value than LDPE, but in the absence of a crack, both materials failed near the lower clamp. With no crack introduced, the maximum extension observed was $7.553 \mathrm{~mm}$ at a load of $53.8 \mathrm{~N}$. However, when the crack length was $20 \mathrm{~mm}$ and the peak load recorded was $31.1 \mathrm{~N}$, the minimum extension observed was $2.6 \mathrm{~mm}$. Figure 8 and Table 3 show the maximum displacement and peak values. Test results for all the specimens are reported in Appendix A, Figure A2. 


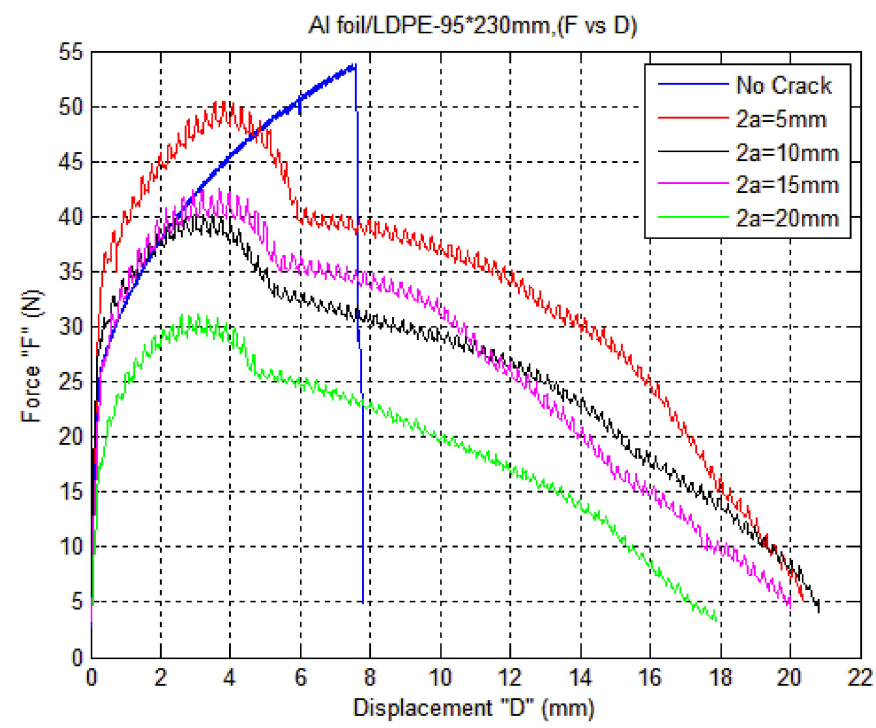

Figure 8. Load vs. displacement of $\mathrm{Al}$ foil/LDPE with a center crack of 0-20 mm.

Table 3. Peak load and maximum displacement of fractured Al foil/LDPE, thickness B of $40 \mu \mathrm{m}$ and dimensions of $230 \mathrm{~mm} \times 95 \mathrm{~mm}$.

\begin{tabular}{ccc}
\hline $\begin{array}{c}\text { Crack Length (2a) } \\
(\mathbf{m m})\end{array}$ & $\begin{array}{c}\text { Maximum Load (F) } \\
\mathbf{( N )}\end{array}$ & $\begin{array}{c}\text { Extension (D) } \\
(\mathbf{m m})\end{array}$ \\
\hline No Crack & 53.8 & 7.553 \\
5 & 50.46 & 3.792 \\
10 & 40.26 & 2.7 \\
15 & 42.51 & 3.666 \\
20 & 31.1 & 2.6 \\
\hline
\end{tabular}

The peak load value for the LDPE with the same specimen size and no crack was recorded as $20.72 \mathrm{~N}$, and the specimen extended $36 \mathrm{~mm}$. The maximum extension observed when the $5 \mathrm{~mm}$ crack was introduced was $30.12 \mathrm{~mm}$, and the peak load was $18.6 \mathrm{~N}$, as shown in Figure 9. These values were used to calculate the other mechanical parameters, which are $=8 \mathrm{MPa}, \mathrm{E}=126.1 \mathrm{MPa}$, and $\mathrm{KI}=0.75 \mathrm{MPa} / \mathrm{m}^{2}$ [35]. These variables were then used in the numerical analysis.

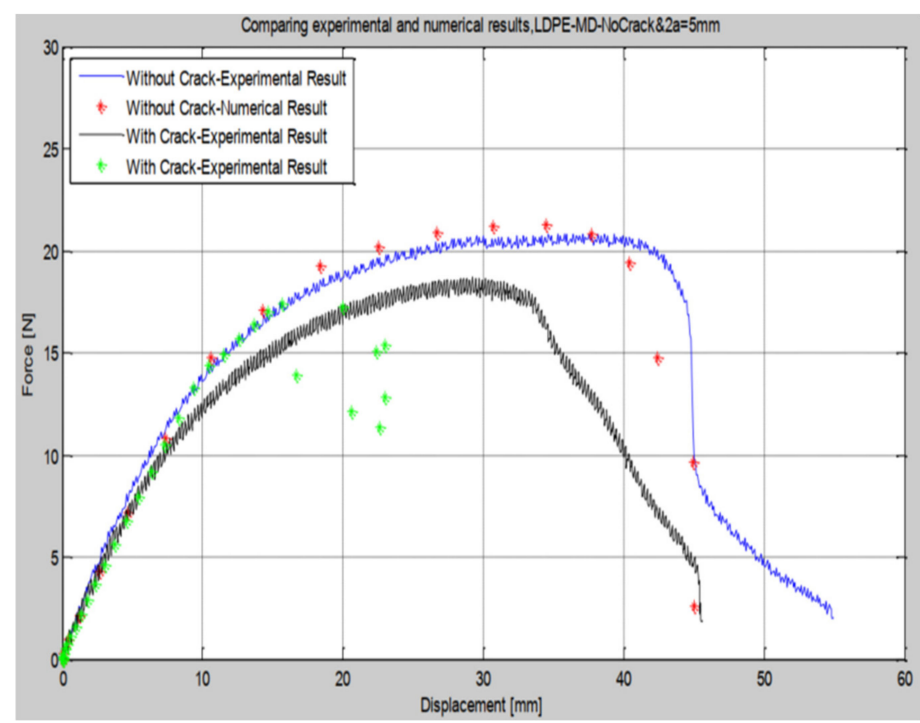

Figure 9. Response of LDPE-MD-95 $230 \mathrm{~mm}$ experimental and numerical results with crack $2 \mathrm{a}=5 \mathrm{~mm}$ and without crack. 


\subsubsection{Case 3: Al-Foil/Adh/LDPE (with Adhesion)}

When $\mathrm{Al} / \mathrm{Adh} / \mathrm{LDPE}$ was tested, the maximum load and extension observed were $44.61 \mathrm{~N}$ and $4.756 \mathrm{~mm}$, respectively, when there was no crack. The maximum load was $23.59 \mathrm{~N}$ and the displacement was $0.653 \mathrm{~mm}$ for the initial crack of $20 \mathrm{~mm}$. The single peak in Figure 10 for each case depicts the behavior of materials in which both materials fail at the same point due to a strong adhesion force between them, which causes them to act as one material. Table 4 summarizes the results. Experimental results are presented in Appendix A, Figure A3 for all the specimens.

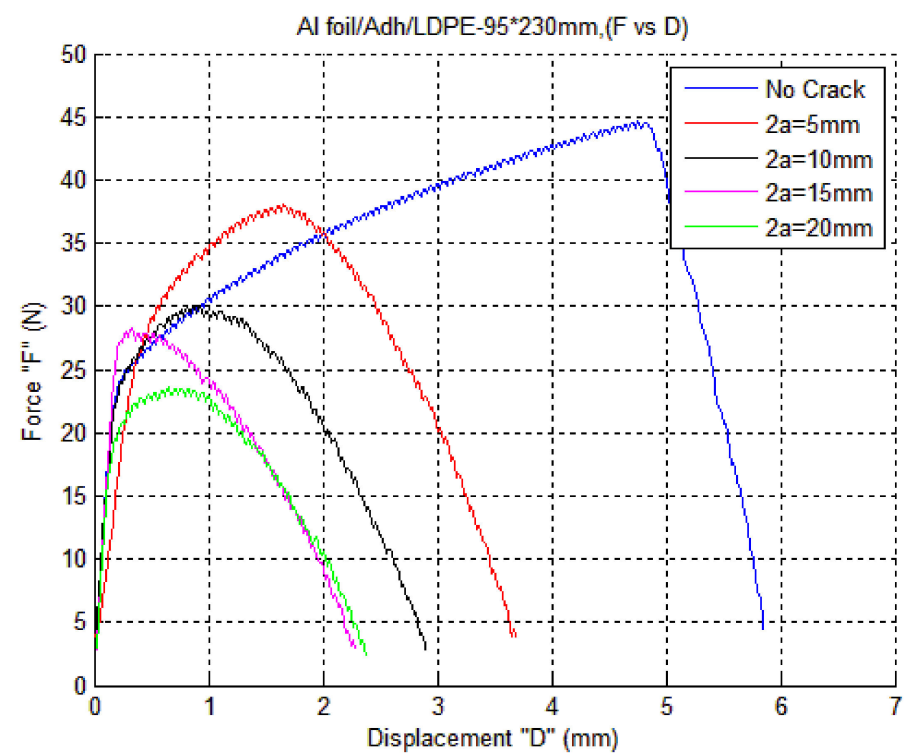

Figure 10. Load vs. displacement of $\mathrm{Al}$ foil/Adh/LDPE for 0-20 mm (center cracked).

Table 4. Load and displacement of fractured Al foil/Adh/LDPE, thickness B of $45 \mu \mathrm{m}$ and dimensions of $230 \mathrm{~mm} \times 95 \mathrm{~mm}$.

\begin{tabular}{ccc}
\hline Crack Length (2a) $(\mathbf{m m})$ & Maximum Load $\mathbf{( F )}(\mathbf{N})$ & Extension $(\mathbf{D}) \mathbf{( m m})$ \\
\hline No. Crack & 44.61 & 4.756 \\
5 & 38.04 & 1.653 \\
10 & 30.07 & 0.863 \\
15 & 28.24 & 0.334 \\
20 & 23.59 & 0.653 \\
\hline
\end{tabular}

\subsubsection{Comparison between Case 2 and Case 3}

Due to the ductility of LDPE, in case 2, the Al broke before the LDPE failed, as shown in Figure 8. For cases with crack lengths ranging from 5 to $20 \mathrm{~mm}$, Al broke before $6 \mathrm{~mm}$, while LDPE did not fail until $20 \mathrm{~mm}$. In case 3, however, due to the strong adhesive bonding between the materials, they acted as one and both broke at the same point, as shown in Figure 10.

\section{Numerical Simulation}

A finite element simulation was carried out in simulation tool ABAQUS Explicit 6.10 by Dassault Systèmes, Vélizy-Villacoublay, France [39] to understand the material behavior clearly. The subsequent steps were followed to develop the exact tensile test model carried out in Section 3. The following assumptions were made to conduct numerical tests in ABAQUS 6.10. As the thickness is less, plane stress was considered. Shell elements were considered and for polymers, a linear elastic, von Mises isotropic plastic material model together with progressive damage was used as the material model. A trial-anderror calibration of continuum material parameters and calibration of fracture material 
parameters were used for the modeling procedure to conduct the tensile test in ABAQUS 6.10/Explicit.

\subsection{Material Parameters Calibration}

The material properties are required in ABAQUS to model the tensile test for Al-foil and LDPE. Experiment results are required to calibrate the data for numerical simulation. Figure 7 depicts a force vs. displacement graph for an Al-foil with no crack. The blue plot was chosen to calibrate the material's properties.

First, the stress vs. strain plot from the experimental results was used to calculate Young's modulus, as shown in Figure 11.

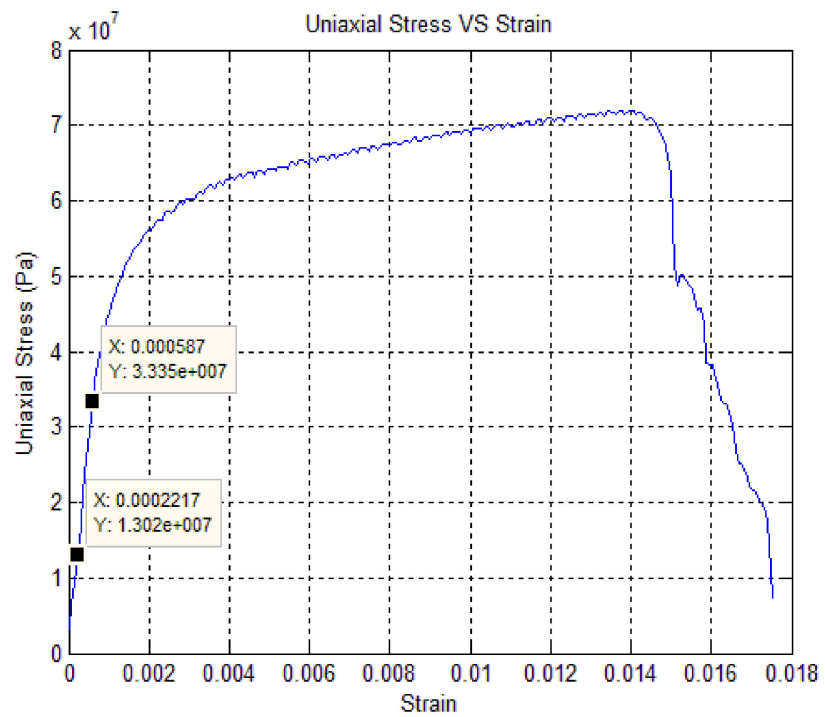

Figure 11. Stress vs. strain graph.

Plasticity is the behavior of a material beyond its elastic limit, which can be calculated using true stress vs. true strain experiments. Analytical methods can be used to calculate true stress and strain. The resulting plot of true stress vs. true strain is shown in Figure 12.

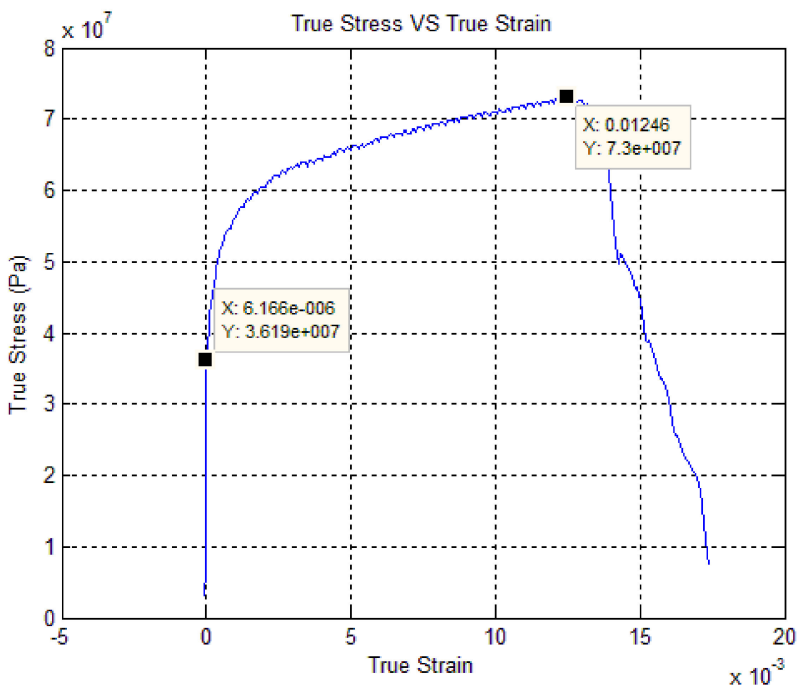

Figure 12. True stress vs. true strain graph for continuum Al-foil.

\subsection{Fracture Material Parameters Calibration}

The following are the components that define the material: the behavior of material under no damage; the behavior of material under damage (damage initiation (point $\mathrm{D}=0$ )); 
and the behavior of material after damage initiation (damage evolution ( $\mathrm{D}=0$ to $\varepsilon_{f}^{p l}$ ). These can be seen in Figure 13.

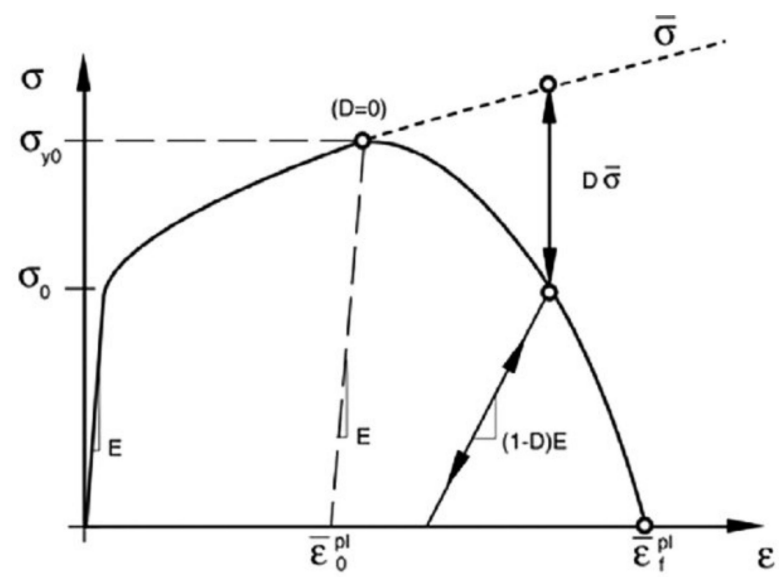

Figure 13. Stress-strain curve under progressive damage degradation.

Damage initiation defines the point at which degradation of stiffness starts. Fracture in a ductile polymer can be caused by two main processes. Nucleation, growth, and coalescence of void cause ductile fracture. Shear band localization causes shear fracture. The behavior of damage growth depends on these above two observations. In ductile metals, the damage caused by nucleation, growth, and coalescence of voids can be predicted by the initiation criterion model. The assumption made in this model is that the plastic strain is a function of stress triaxiality and strain rate for the onset of damage. Damage evolution defines the behavior of a material after damage initiation. It means that once initiation is caused, it defines the rate of degradation of the material stiffness [40].

Figure 13 describe the stress-strain behavior of a material under damage, where, $\mathrm{E}=$ Young's Modulus, $\mathrm{D}=$ damage variable, $\sigma_{y 0}=$ yield stress when damage onset occurs $($ at $\mathrm{D}=0), \varepsilon_{0}^{p l}=$ equivalent plastic strain at damage onset $($ at $\mathrm{D}=0), \varepsilon_{f}^{p l}=$ plastic strain when failure occurs (at $\mathrm{D}=1$ ).

All numerical parameters were calibrated by experimental measurement. In Table 5, fracture strains were calculated from the displacement response of the tensile test. As pre-cracked samples were tested, we assumed the strain had fully localized around the cracked surface. The stress triaxiality value was chosen in and of -5 and 5 , which made the fracture strain in the material constitutive stress triaxiality independent. Finally, the displacement at failure, which is a FE-simulation material failure parameter, was calibrated by inverse modeling of the force displacement curve from experiment.

Table 5. The ductile damage initiation damage evolution values for aluminum foil and LDPE.

\begin{tabular}{ccccc}
\hline Materials & Fracture Strain & $\begin{array}{c}\text { Stress } \\
\text { Triaxiality }\end{array}$ & Strain Rate & $\begin{array}{c}\text { Displacement at } \\
\text { Failure (mm) }\end{array}$ \\
\hline \multirow{2}{*}{ Aluminum Foil } & 0.0001 & -5 & 0 & 0.075 \\
\hline \multirow{2}{*}{ LDPE } & 0.0001 & 5 & 0 & 0.9 \\
\hline
\end{tabular}

\subsection{Numerical Results and Discussion}

By using the Young Modulus equation and (Figure 11), the values within the elastic limit help to calculate Young's Modulus. For aluminum: Young's Modulus $(E)=55.653 \mathrm{GPa}$, Poisson's ratio $(v)=0.3$, thickness $(t)=9$ microns. Similarly, Young's modulus calculated for LDPE was $(\mathrm{E})=126.1 \mathrm{Mpa}$. 


\subsubsection{Aluminum Foil (No Crack)}

Experiment results were used to calculate the material's properties. Plasticity values were calculated analytically based on the results. The results of both numerical and experimental calculations are nearly identical. Figure 14 depicts the response of experimental and numerical results. This leads us to the conclusion that the Al-foil can be modeled in the finite element software ABAQUS plasticity values.

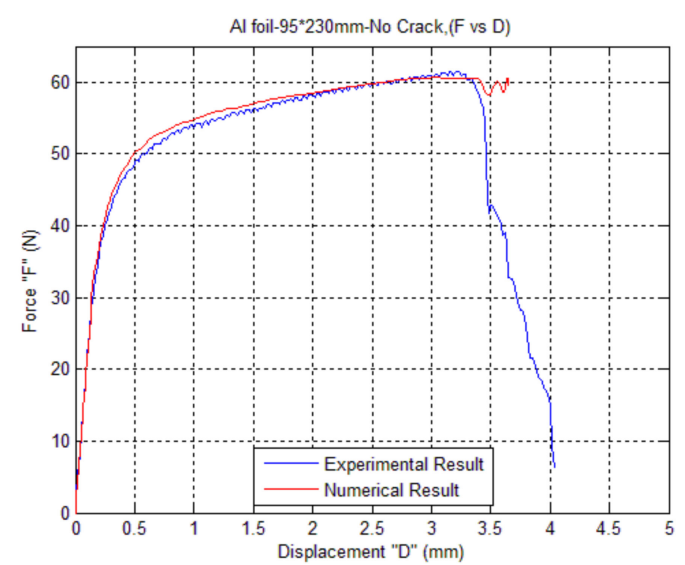

Figure 14. Force vs. displacement graph of aluminum foil (No Crack).

After calibrating fracture material parameters, they were compared with experimental results when the Young's modulus value of $55.63 \mathrm{GPa}$, and the plasticity values (Appendix B, Table A1) were used; good results were obtained with the damage initiation of 0.0001 and damage evolution of $0.075 \mathrm{~mm}$ presented in Table 5 . The values of stress triaxiality and strain rate remained fixed in this numerical simulation.

\subsubsection{LDPE}

The properties of LDPE used in the subsequent theoretical and experimental analysis which are obtained from [35] are presented in Table 5 and Appendix B, Table A2.

\subsubsection{Aluminum Foil ( $5 \mathrm{~mm}$ Crack)}

All of the continuum and fractsure material parameters mentioned in Section 4.3.1, such as Young's modulus, plasticity, damage initiation, and damage evolution, remained constant for the specimen with a crack length of $5 \mathrm{~mm}$.

When the experimental and numerical results are compared, Figure 15, it is clear that the material behavior is the same within the elastic limit, but there are some discrepancies in the material behavior in the plastic region.

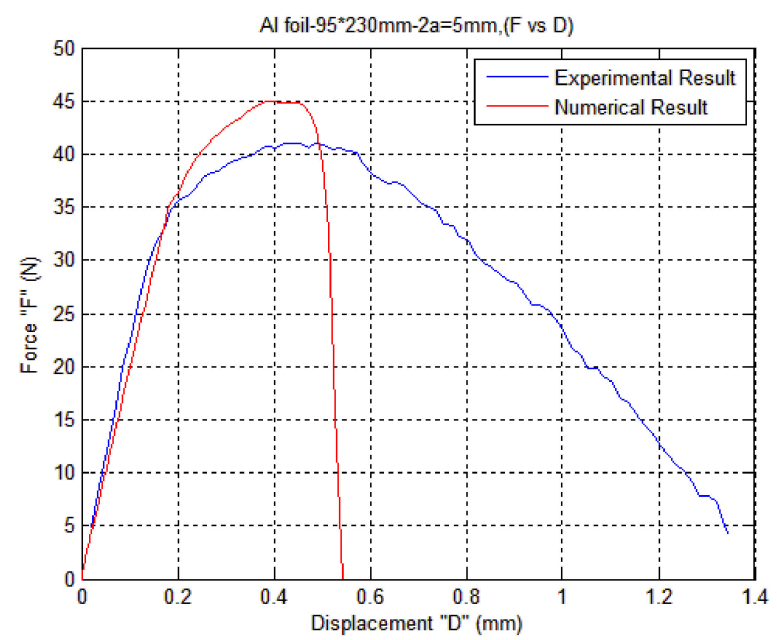

Figure 15. Force vs. displacement of aluminum foil with $5 \mathrm{~mm}$ Crack. 


\subsubsection{Aluminum Foil/LDPE Laminated (No Crack)}

To simulate the ABAQUS model, all of the fracture material parameters such as Young's modulus, plasticity, damage initiation, and damage evolution for both Al-foil and LDPE, as mentioned in Sections 4.3.1 and 4.3.2, respectively, were used. When the experimental and numerical results are compared Figure 16, it is clear that the material behavior in both cases differs to some extent.

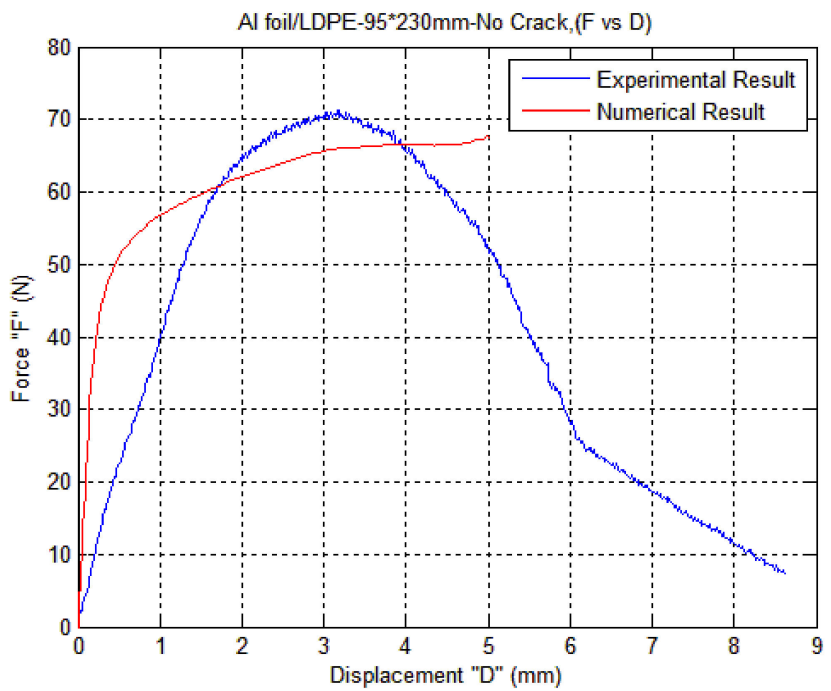

Figure 16. Force vs. displacement of aluminum foil/LDPE without crack.

\section{Results and Discussion}

Critical stresses were calculated for Al-foil with different crack lengths $(5,10,15$, 20, and $45 \mathrm{~mm}$ ). The following fracture toughness graph was plotted using the LEFM, Equation (5), the strip yield model, Equation (7), and the experimental results for the Al-foil, which shows the normalized critical stresses vs. normalized crack length.

The strip yield model and LEFM's theoretical calculations show a strong correlation with the experimental data. As depicted in Figure 17, the Al-foil with a thickness of 9 microns has a fracture toughness of $6.39 \mathrm{MPa} / \mathrm{m}^{2}$ For the Al-foil with a thickness of 6.42 microns, the fracture toughness was calculated using mechanical parameters reported in [23] was $\mathrm{KC}=6.1 \mathrm{MPa} / \mathrm{m}^{2}$.

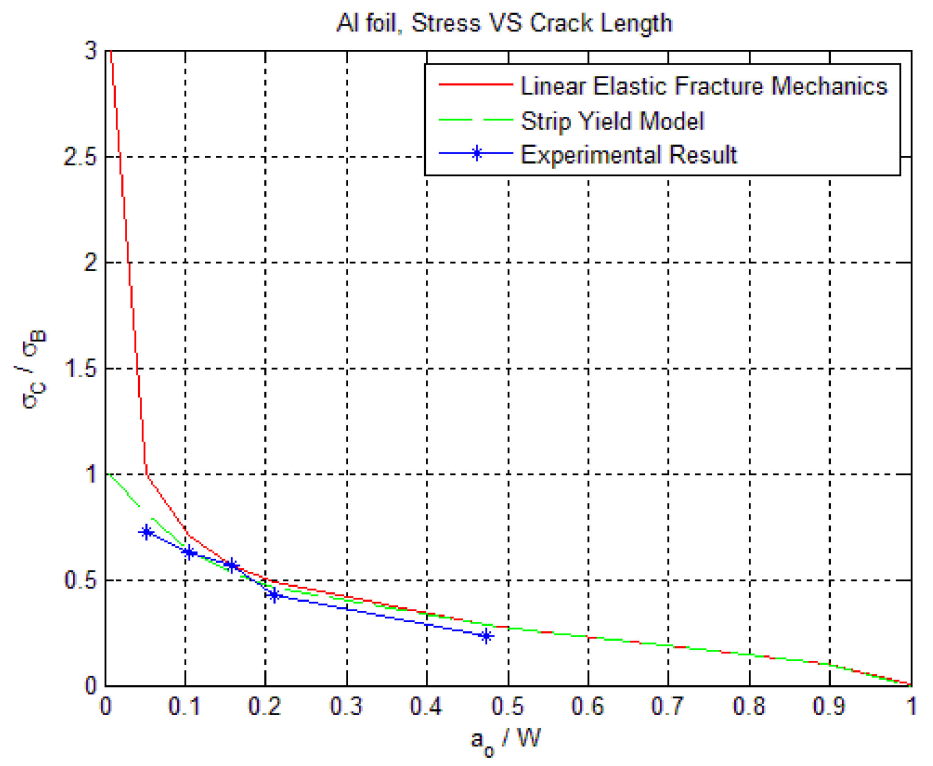

Figure 17. Fracture toughness graph. 
When the experimental and numerical findings for $\mathrm{Al}$ foil and Al/LDPE were examined Figure 18, it was discovered that the experimental and numerical results for Al foil and Al foil/LDPE exhibited nearly the same behavior until the peak and then altered due to LDPE. However, the results of material laminated in the Blekinge Institute of Technology Lab were not the same as those discussed above. Due to the contact with PET and the heated surface of the machine used for lamination, material properties may alter. Another reason for this is because Al-foil failed first, followed by LDPE. This resulted in oscillation, which influenced the material properties and results.

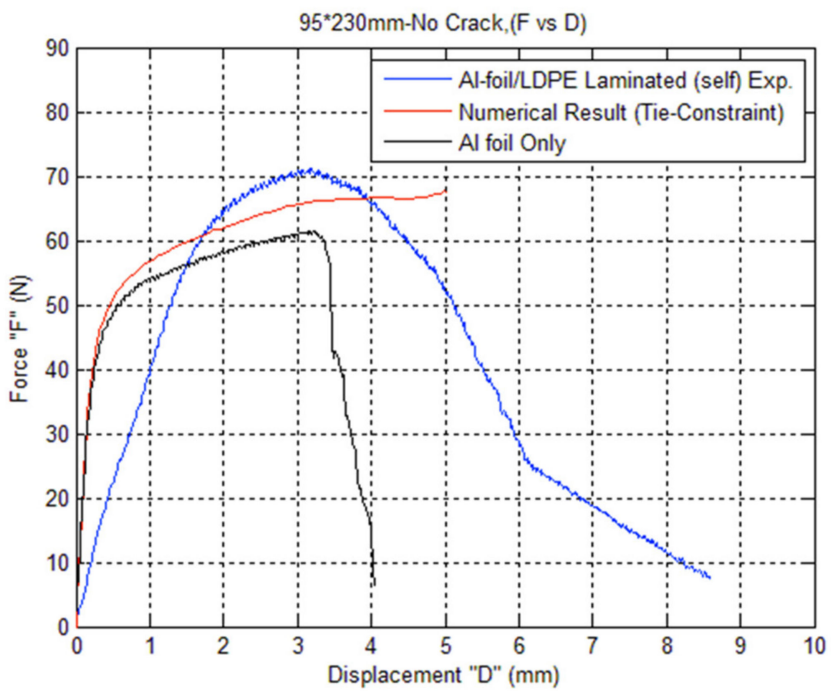

Figure 18. Comparison of experimental and numerical analysis.

When comparing the experimental results for Al foil/LDPE with no and full adhesion, as shown in Figure 19, it was discovered that they showed the same behavior until peak and then changed behavior because the material behaved as a different material with new material parameters during full adhesion. This is due to the strong adhesive bonding between the materials as presented in Figure 16.

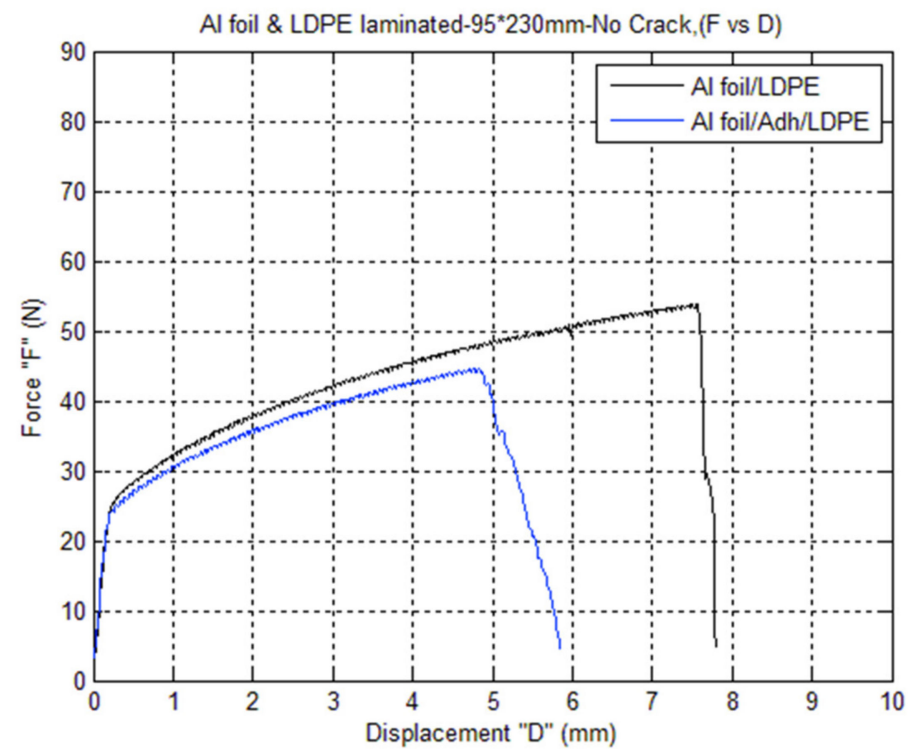

Figure 19. Comparison of experimental results between $\mathrm{Al}$ foil/LDPE and Al/Adh/LDPE.

In the case of laminated Al-foil/LDPE (without adhesion), the material's behavior in numerical and physical tests is dynamic along the displacement, which could be due to a 
number of factors, including the fact that both materials were in contact with Polyethylene Terephthalate (PET) to avoid burning and sticking of materials with paper. This may lead to a change in the material's properties. Second, both materials retained their properties, so that Al-foil broke first, followed by LDPE, which is more ductile than Al-foil. The other reason is that the Al-foil failed first, followed by the LDPE. This resulted in oscillation, which influenced the material properties and results.

The failure occurred at the same force and displacement in both materials while performing experiments on aluminum foil/Adh/LDPE (full adhesion). Due to the strong adhesive bonding between the materials, they behaved as if they were one material, allowing us to conclude that the strong adhesion changes the material parameters.

\section{Conclusions}

- Different material properties were determined in this study by developing physical test and FE modeling procedures. The experiments were carried out on Al-foil, aluminum foil laminated with LDPE, with and without adhesion. Material parameters were calibrated for use in the numerical test study. The design of experiment technique was used to determine the material's Young's modulus, plasticity, damage initiation, and damage evolution. For Al-foil, the theoretical result using LEFM and modified strip yield model was showing a close relation with the obtained experimental results.

- The fracture toughness $\mathrm{K}_{\mathrm{C}}$ obtained for the Al-foil with thickness of 9 microns was $6.39 \mathrm{MPam}^{1 / 2}$. An earlier study on the same grade Al-foil reported the fracture toughness $\mathrm{K}_{\mathrm{C}}=6.1 \mathrm{MPam}^{1 / 2}$ for thickness of 6.42 microns.

- For the case of laminated Al-foil/LDPE (without adhesion), the behavior of the material in the numerical and physical tests was dynamic along the displacement and there may be number of reasons, such as the fact that Al-foil and LDPE were laminated by a lamination machine and were in contact with PET to avoid the burning and sticking of materials with paper. This may have caused the change in the material properties.

- Failure of Al-foil before the LDPE in case of Al foil/LDPE (without adhesion) cause the specimen oscillation, so vibration can also be a cause of change in material behavior when analyzed numerically.

- In the case of $\mathrm{Al}$ foil/Adh/LDPE, both materials broke at the same point so it can be concluded that the strong adhesion force between laminates can change the properties and the materials act as one.

This research can be expanded in the future to calculate the fracture toughness value of laminated materials. Furthermore, the FE modeling strategy can be defined for materials with full adhesion. Under the microscope, bonded material delamination can be defined and studied. Adhesives and their effects on the properties of bonded materials can be studied.

Author Contributions: Supervised all the project and literature review regarding this paper, U.S.; Supervision of the project including literature review and write-up, B.S.; Did all the experimental work and manuplate the data of this paper, M.S.I.; Look after the experimental work, completed illustration and data interpretation, K.M.; Managed the raw materials and give a proper guidance for materials usage and safety, D.S.I.; Helped in paper revisions and data explanations, O.O.A.; Funding acquisition, N.A.; Provided financial help, Z.I.Z.; Helped in data explainations, Z.M.E.-B. All authors have read and agreed to the published version of the manuscript.

Funding: Supported by National Key Research and Development Program of China (Grant No. 2019yFB2006404) and the Taif Researchers Supporting Project (TURSP-2020/42), Taif University, Taif, Saudi Arabia.

Institutional Review Board Statement: Not applicable for this study.

Informed Consent Statement: Not applicable for this study.

Data Availability Statement: Dataset will be provided by coressponding author upon reasonable request. No publicly archived dataset was utilized in this study. 
Conflicts of Interest: The authors declare no conflict of interest.

\section{Appendix A}

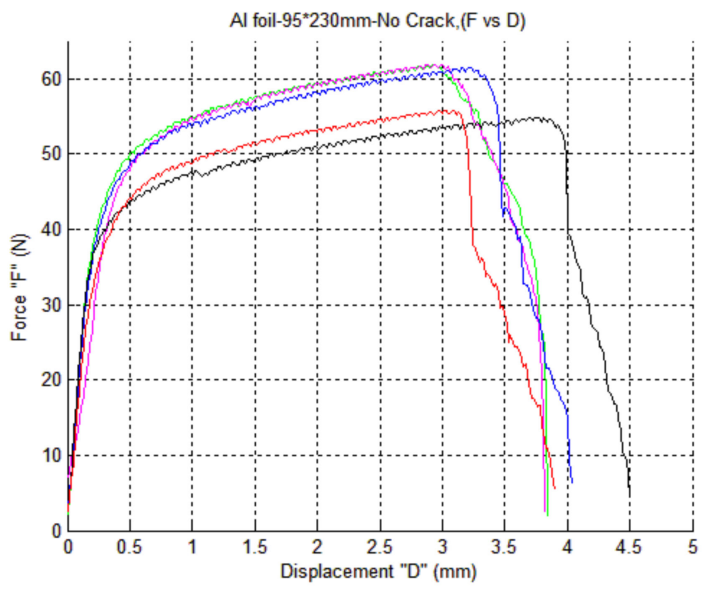

(a)

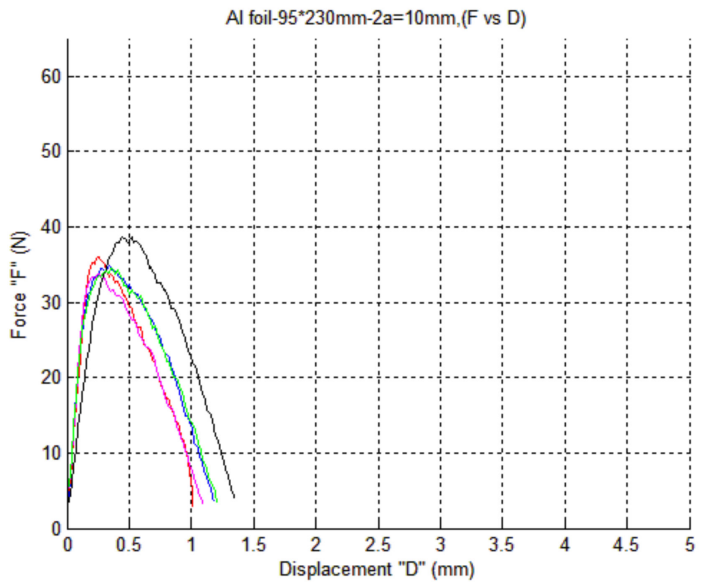

(c)

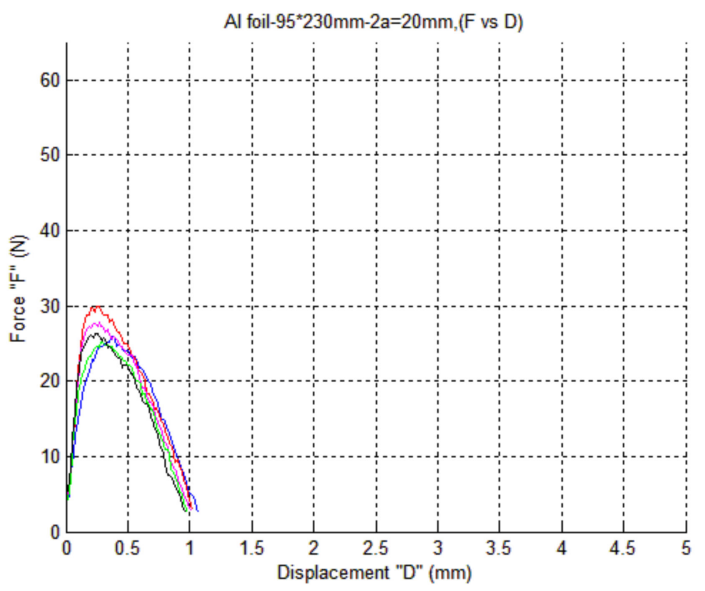

(e)

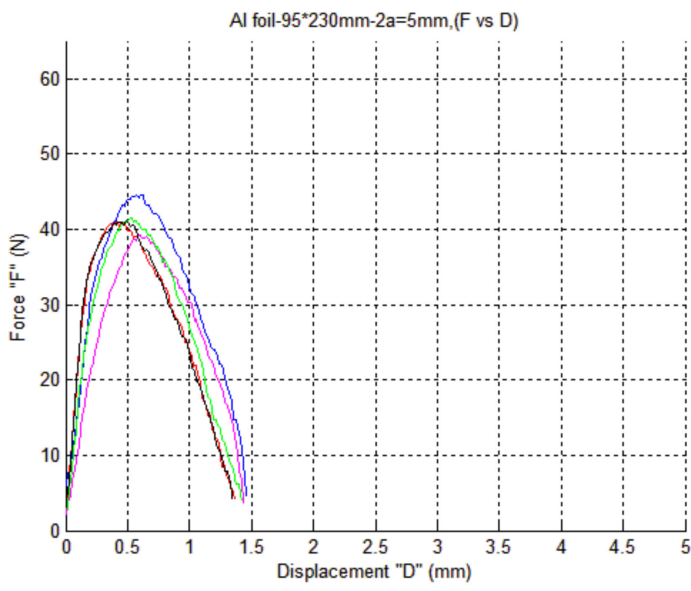

(b)

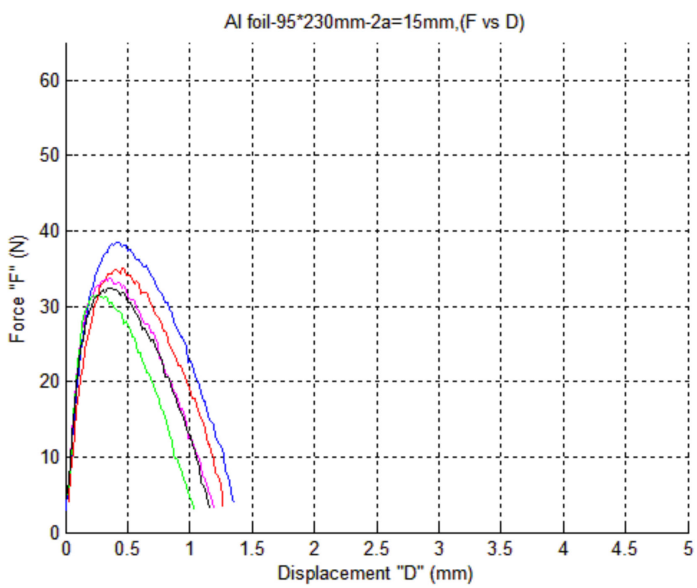

(d)

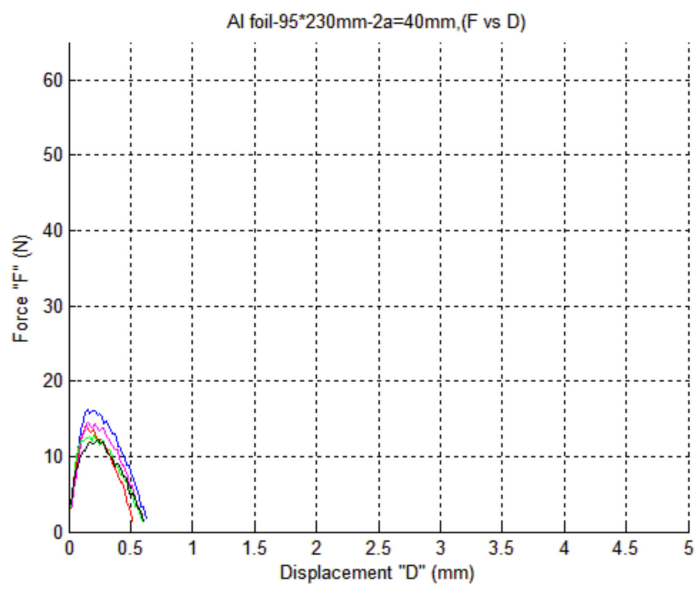

(f)

Figure A1. Experimental results for aluminum foil. (a) F vs. D for $0 \mathrm{~mm}$ crack, (b) F vs. D for 5 mm crack, (c) F vs. D for 10 mm crack, (d) F vs. D for 15 mm crack, (e) F vs. D for 20 mm crack, (f) F vs. D for 40 mm crack. 


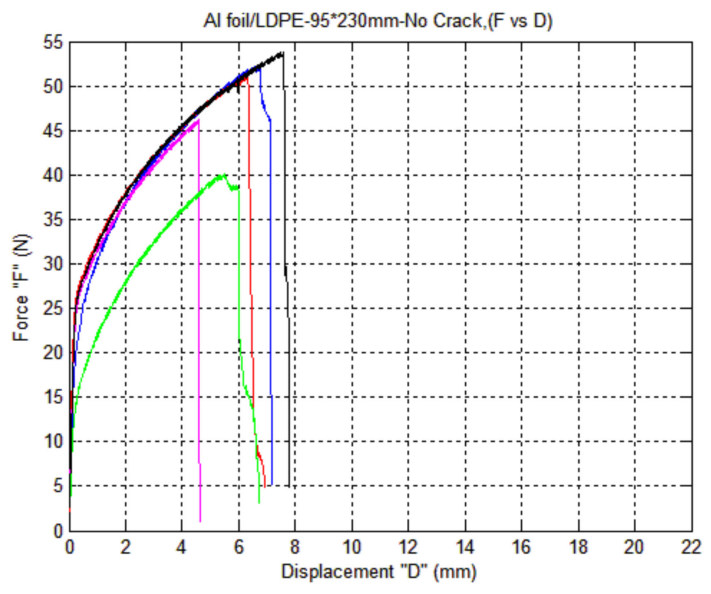

(a)

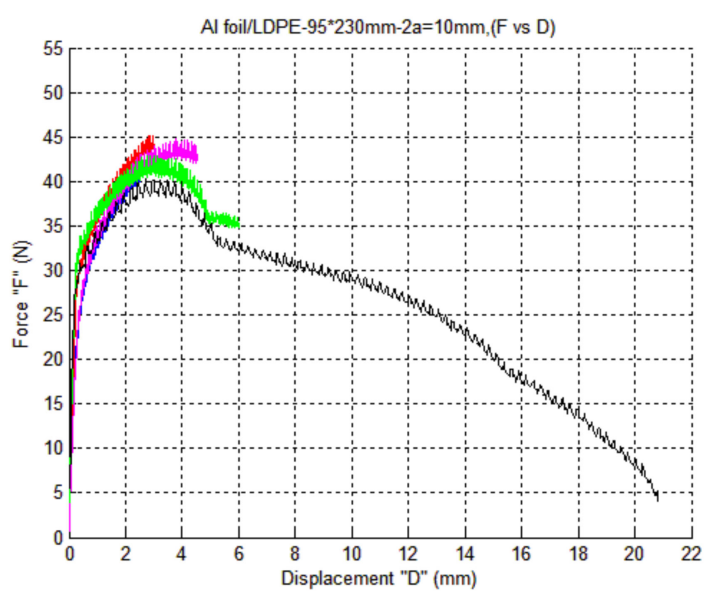

(c)

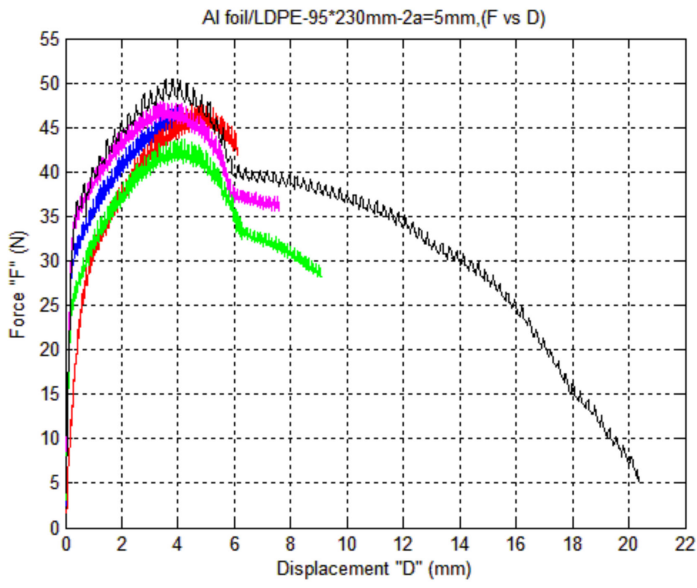

(b)

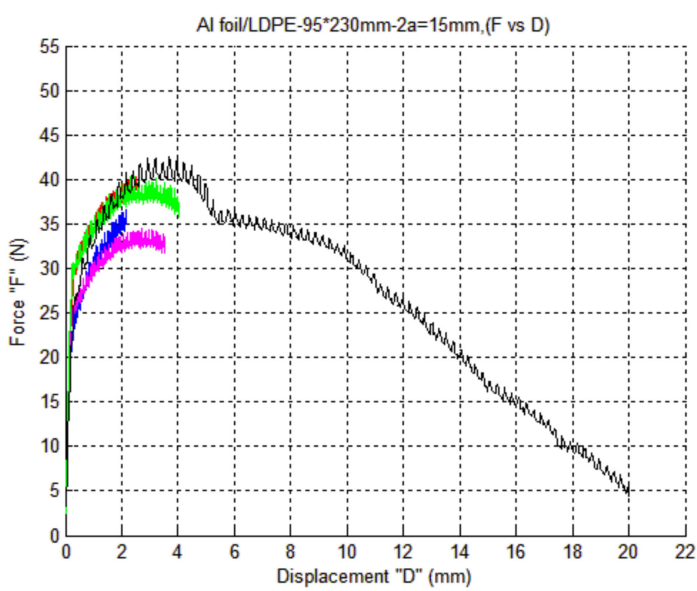

(d)

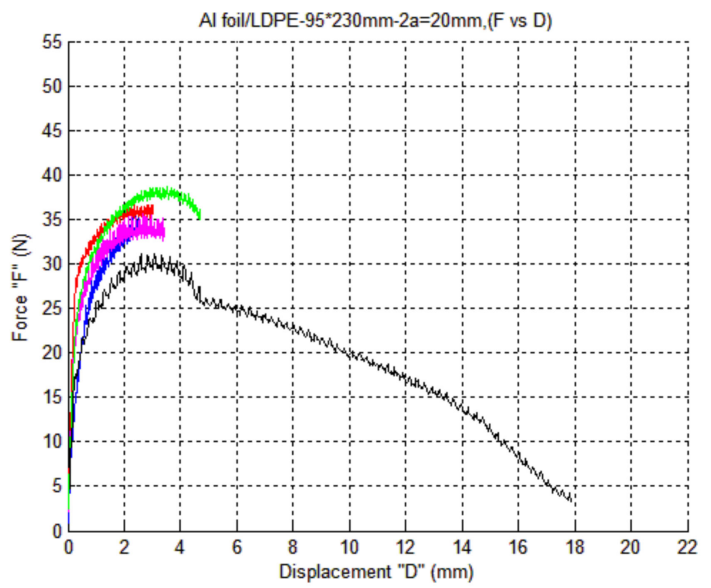

(e)

Figure A2. Experimental results for aluminum foil/LDPE. (a) F vs. D for 0 mm crack, (b) F vs. D for 5 mm crack, (c) F vs. D for $10 \mathrm{~mm}$ crack, (d) F vs. D for $15 \mathrm{~mm}$ crack, (e) F vs. D for $20 \mathrm{~mm}$ crack. 


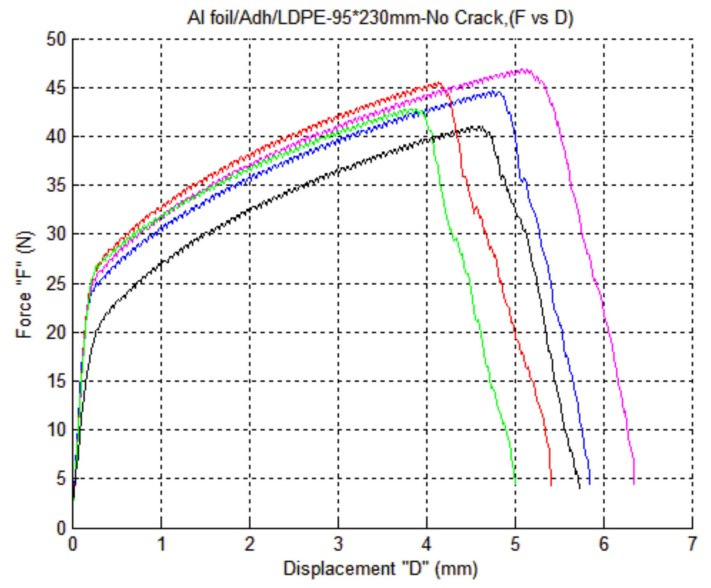

(a)

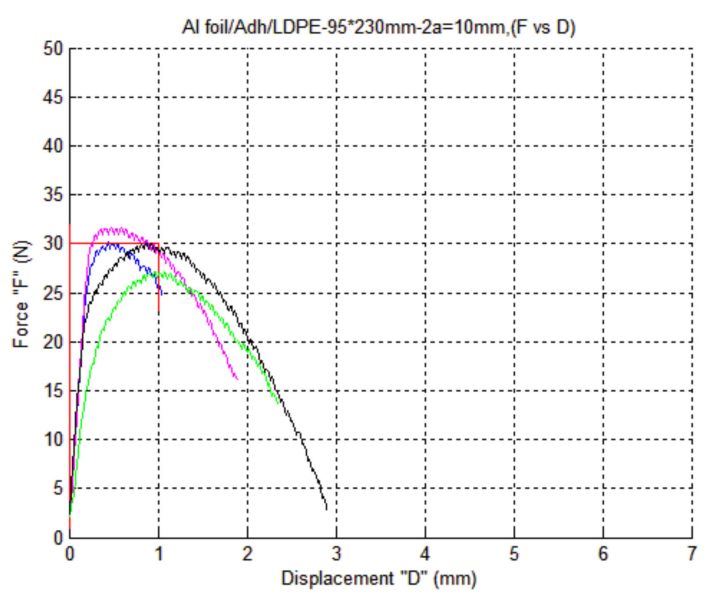

(c)

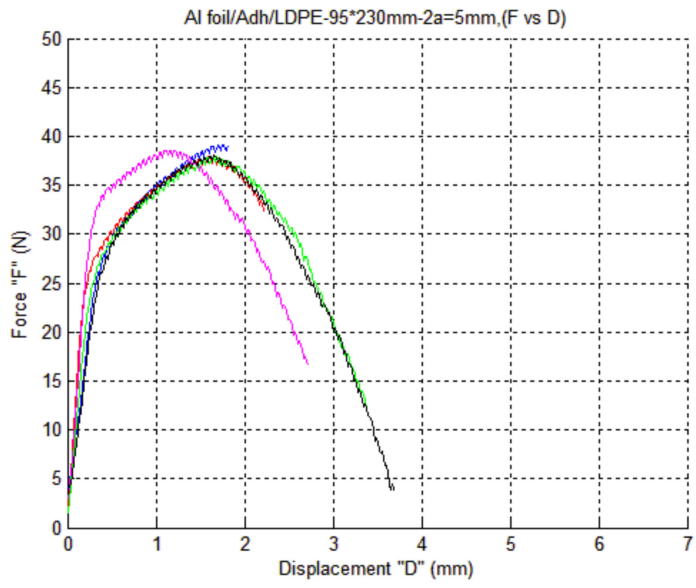

(b)

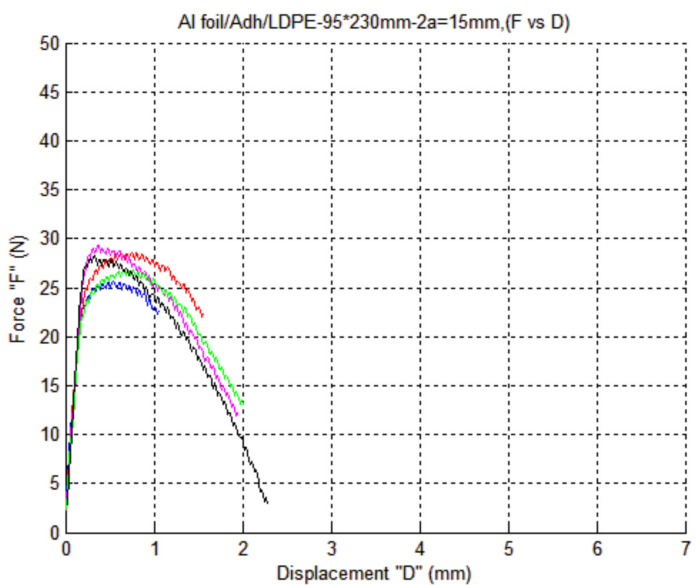

(d)

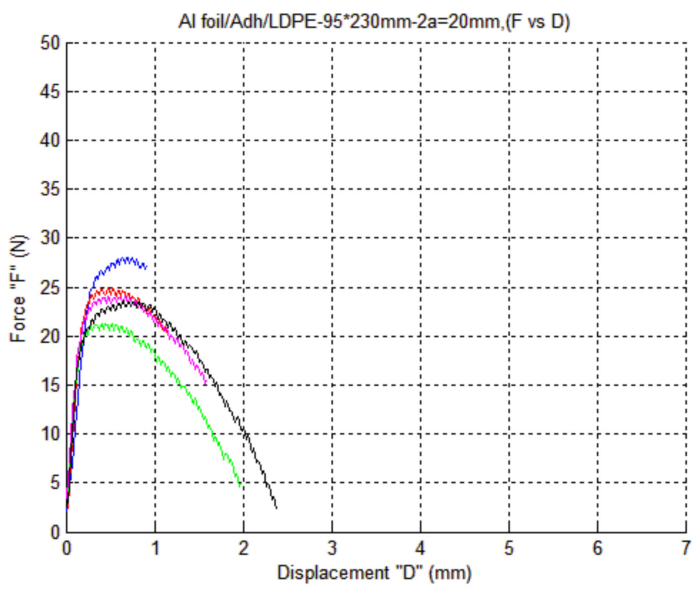

(e)

Figure A3. Experimental results for aluminum foil/Adh/LDPE. (a) F vs. D for 0 mm crack, (b) F vs. D for 5 mm crack, (c) F vs. D for $10 \mathrm{~mm}$ crack, (d) F vs. D for $15 \mathrm{~mm}$ crack, (e) F vs. D for $20 \mathrm{~mm}$ crack. 


\section{Appendix B}

Table A1. Yield stress and plastic strain of aluminum foil.

\begin{tabular}{ccc}
\hline Nos. & Yield Stress (MPa) & Plastic Strain \\
\hline 1 & 36.19 & 0 \\
2 & 42.54 & 0.0001096 \\
3 & 45.12 & 0.000211 \\
4 & 48.13 & 0.0003004 \\
5 & 51.16 & 0.0004633 \\
6 & 54.11 & 0.0007017 \\
7 & 57.38 & 0.001147 \\
8 & 60.35 & 0.00182 \\
9 & 62.95 & 0.003004 \\
10 & 64.77 & 0.004132 \\
11 & 66.56 & 0.005547 \\
12 & 68.58 & 0.007468 \\
13 & 70.63 & 0.009318 \\
14 & 72.12 & 0.01117 \\
15 & 73 & 0.01246 \\
\hline
\end{tabular}

Table A2. Yield stress and plastic strain of LDPE.

\begin{tabular}{ccc}
\hline Nos. & Yield Stress (MPa) & Plastic Strain \\
\hline 1 & 5.332 & 0 \\
2 & 5.444 & 0.00134 \\
3 & 5.68 & 0.0022 \\
4 & 6 & 0.00427 \\
5 & 6.16 & 0.00569 \\
6 & 6.3 & 0.0065 \\
7 & 6.459 & 0.0079 \\
8 & 6.511 & 0.0083 \\
9 & 6.62 & 0.0093 \\
10 & 6.78 & 0.01107 \\
11 & 6.90 & 0.0124 \\
12 & 7.08 & 0.0147 \\
13 & 7.14 & 0.0148 \\
14 & 7.21 & 0.0164 \\
15 & 7.328 & 0.0184 \\
16 & 7.412 & 0.0193 \\
17 & 7.553 & 0.0227 \\
18 & 7.638 & 0.0246 \\
19 & 7.80 & 0.0278 \\
20 & 7.92 & 0.0313 \\
21 & 8.02 & 0.0330 \\
22 & 8.136 & 0.0365 \\
23 & 8.26 & 0.04 \\
24 & 8.35 & 0.0425 \\
25 & 8.73 & 0.0696 \\
\hline
\end{tabular}

\section{References}

1. Islam, M.S. Fracture and Delamination in Packaging Materials: A Study of Experimental Methods and Simulation Techniques. Ph.D. Thesis, Blekinge Tekniska Högskola, Karlshamn, Sweden, 2019.

2. Islam, M.S.; Alfredsson, K.S. Peeling of metal foil from a compliant substrate. J. Adhes. 2021, 97, 672-703. [CrossRef]

3. Marsh, K.; Bugusu, B. Food packaging-Roles, materials, and environmental issues. J. Food Sci. 2007, 72, R39-R55. [CrossRef]

4. Geueke, B.; Groh, K.; Muncke, J. Food packaging in the circular economy: Overview of chemical safety aspects for commonly used materials. J. Clean. Prod. 2018, 193, 491-505. [CrossRef]

5. Shin, J.; Selke, S.E.M. Chapter 11 Food Packaging. Food Processing: Principles and Applications; John Wiley \& Sons: Hoboken, NJ, USA, 2014. 
6. Brostow, W.; Lobland, H.E.H.; Khoja, S. Brittleness and toughness of polymers and other materials. Mater. Lett. 2015, 159, 478-480. [CrossRef]

7. Kao-Walter, S. On the Fracture of Thin Laminates. Ph.D. Thesis, Blekinge Institute of Technology, Karlskrona, Sweden, 2004.

8. Tryding, J. In Plane Fracture of Paper. Ph.D. Thesis, Lund Institute of Technology, Lund, Sweden, 1996.

9. Hägglund, R.; Isaksson, P. Analysis of localized failure in low-basis-weight paper. Int. J. Solids Struct. 2006, 43, 5581-5592. [CrossRef]

10. Isaksson, P.; Hägglund, R.; Gradin, P. Continuum damage mechanics applied to paper. Int. J. Solids Struct. 2004, 41, 4731-4755. [CrossRef]

11. Islam, M.S.; Zhang, D.; Mehmood, N.; Kao-Walter, S. Study of shear dominant delamination in thin brittle-high ductile interface. Procedia Struct. Integr. 2016, 2, 152-157. [CrossRef]

12. De-feng, Z.; Md. Shafiqu, I.; Eskil, A.; Sharon, K.-W. Modeling and study of fracture and delamination in a packaging laminate. In Proceedings of the 3rd International Conference on Material Engineering and Application (ICMEA 2016), Shanghai, China, 12-13 November 2016.

13. Li, T.; Suo, Z. Ductility of thin metal films on polymer substrates modulated by interfacial adhesion. Int. J. Solids Struct. 2007, 44, 1696-1705. [CrossRef]

14. Li, T.; Suo, Z. Deformability of thin metal films on elastomer substrates. Int. J. Solids Struct. 2006, 43, 2351-2363. [CrossRef]

15. Suo, Z.; Vlassak, J.; Wagner, S. Micromechanics of macroelectronics. China Particuology 2005, 3, 321-328. [CrossRef]

16. Li, T.; Zhang, Z.; Michaux, B. Competing failure mechanisms of thin metal films on polymer substrates under tension. Theor. Appl. Mech. Lett. 2011, 1, 041002. [CrossRef]

17. Shahid, S.; Gukhool, W. Experimental Testing and Materialmodeling of Anisotropy in Injection Moulded Polymer Materials. Master's Thesis, Blekinge Institiute of Technology, Karlskrona, Sweden, 2020.

18. Danielsson, M.; Parks, D.M.; Boyce, M.C. Three-dimensional micromechanical modeling of voided polymeric materials. J. Mech. Phys. Solids 2002, 50, 351-379. [CrossRef]

19. Sedighiamiri, A.; Govaert, L.E.; Van Dommelen, J.A.W. Micromechanical modeling of the deformation kinetics of semicrystalline polymers. Polym. Sci. Part B Polym. Phys. 2011, 48, 1297-1310. [CrossRef]

20. Chen, S.H.; Wang, T.C.; Kao-Walter, S. A crack perpendicular to the bimaterial interface in finite solid. Int. J. Solids Struct. 2003, 40, 2731-2755. [CrossRef]

21. Kao-Walter, S.; Ståhle, P.; Chen, S.H. A finite element analysis of a crack penetrating or deflecting into an interface in a thin laminate. Key Eng. Mater. 2006, 312, 173-178. [CrossRef]

22. Kao-Walter, S.; Ståhle, P.; Hägglund, R. Fracture toughness of a laminated composite. Eur. Struct. Integr. Society. 2003, 32, 355-364. [CrossRef]

23. Kao-Walter, S. Mechanical and Fracture Properties of Thin Al-Foil; Blekinge Tekniska Högskola Forskningsrapport: Karlskrona, Sweden, 2001; ISSN 11031581.

24. He, G.; Li, J.; Zhang, F.; Lei, F.; Guo, S. A quantitative analysis of the effect of interface delamination on the fracture behavior and toughness of multilayered propylene-ethylene copolymer/low density polyethylene films by the essential work of fracture (EWF). Polymer 2014, 55, 1583-1592. [CrossRef]

25. Iqbal, M.S.; Muhammadi, A.B. Tearing Fracture and Microscopic Analysis of Laminate Toward Sustainable Packaging. Master's Thesis, Blekinge Institute of Technology, Karlskrona, Sweden, 2007.

26. Skanse, H. Investigation of Mechanical Tearing and How it can Be Applied in Package Open Ability Prediction. Master's Thesis, Lund Institute of Technology, Lund, Sweden, 2009.

27. Karmlid, O. Simulation and Testing of Crack Sensitivity in TFA Packaging Material. Master's Thesis, Lund University, Lund, Sweden, 2011.

28. Min, H. Study of Two Models for Tearing Resistance Assesment Using Essential Work of Fracture Method; Blekinge Institute of Technology: Karlskrona, Sweden, 2008.

29. Kao-Walter, S.; Dahlström, J.; Karlsson, T.; Magnusson, A. A study of the relation between the mechanical properties and the adhesion level in a laminated packaging material. Mech. Compos. Mater. 2004, 40, 29-36. [CrossRef]

30. Kao-Walter, S.; Mfoumou, E. Fracture Toughness Testing of Non Standard Specimens; Blekinge Institute of Technology: Karlskrona, Sweden, 2004.

31. Anderson, T.L. Fracture Mechanics Fundamentals and Applications, 3rd ed.; CRC Press Taylor \& Francis Group: Boca Raton, FL, USA, 2005.

32. Kao-Walter, S.; Ståhle, P. Fracture Behaviour of a Thin Al-Foil-Measuring and Modelling of the Fracture Processes. In Proceedings of the Third International Conference on Experimental Mechanics, Beijing, China, 15-17 October 2001; pp. 25-256.

33. Dugdale, D.S. Yielding of steel sheets containing slits. J. Mech. Phys. Solids 1960, 8, 100-104. [CrossRef]

34. Fracture Toughness. Center, N.E.R. Toughness. 2018. Available online: https://www.nde-ed.org/EducationResources/ CommunityCollege/Materials/Mechanical/Toughness.html (accessed on 21 August 2020).

35. Jemal, A.; Katangoori, R.R. Fracture Mechanics Applied in Thin Ductile Packaging Materials-Experiments with Simulations. Master's Thesis, Blekinge Institute of Technology, Karlskrona, Sweden, 2011.

36. Baldan, A. Adhesively-bonded joints and repairs in metallic alloys, polymers and composite materials: Adhesives, adhesion theories and surface pretreatment. J. Mater. Sci. 2004, 39, 1-49. [CrossRef] 
37. Creton, C.A. Materials science of pressure sensitive adhesives, materials science and technology. Process. Mater. 1997, 18, 434-439.

38. Krenk, S. Non-Linear Modeling and Analysis of Solids and Structures; Cambridge University Press: Cambridge, UK, 2009.

39. Systèmes, D. Introduction to Abaqus Scripting; Dassault Systèmes: Vélizy-Villacoublay, France, 2009.

40. Shi, Y.; Swait, T.; Soutis, C. Modelling damage evolution in composite laminates subjected to low velocity impact. Compos. Struct. 2012, 94, 2902-2913. [CrossRef] 